\title{
Management of Post-Traumatic Complications by Interventional Ultrasound: a Review
}

\author{
Mauro Zago $^{1} \cdot$ Samantha Bozzo $^{1} \cdot$ Diego Mariani $^{2}$
}

Published online: 6 August 2016

(C) Springer International Publishing AG 2016

\begin{abstract}
Purpose of Review We reviewed the current literature to assess the feasibility of ultrasound-assisted and ultrasoundguided procedures for the treatment of post-traumatic complications and to address the indications and techniques of procedures.

Recent Findings Non-operative strategies have been introduced in the treatment of severe trauma, and consequently, the incidence of some post-traumatic complications has increased. US can be useful both for the initial assessment of trauma patients and for the treatment of complications.

Summary Ultrasound-guided and ultrasound-assisted procedures as a therapeutic tool in the management of post-trauma settings are probably underused, in comparison with their successful use in other acute settings. Some new possible fields of clinical researches are suggested.
\end{abstract}

Keywords Interventional ultrasound · Trauma complications · Retained hemothorax - Small pneumothorax · Liver trauma $\cdot$ Morel-Lavallée lesion

This article is part of the Topical Collection on Minimally Invasive Surgical Techniques for Trauma

Mauro Zago

maurozago.md@gmail.com

1 General Surgery Department, Minimally Invasive Surgery Unit, Policlinico San Pietro, via Forlanini, 15, Ponte San Pietro, BG, Italy

2 General Surgery Department, Legnano Hospital, ASST Ovest Milanese, Legnano, MI, Italy

\section{Introduction}

In the last decades the use of ultrasound in the emergency department setting by non-radiologist doctors has been introduced into clinical practice. Ultrasound (US) imaging is characterized by many advantageous features such as portability, easy access, accuracy, and cost-effectiveness. Also, it is userfriendly in assessing unstable patients and requires no ionizing radiations. These are characteristics that make ultrasonography suited for surgical practice and dynamic clinical decisionmaking $[1,2]$.

Surgeon-performed US in trauma patients became a topic of interest in the early 1990s [1, 3] and later, in 1999, the FAST (focused assessment with sonography for trauma) consensus conference credentialed the use of sonography in the initial assessment of trauma patients. The natural evolution toward the extended FAST (E-FAST) has spread its use to the evaluation of chest injuries $[4,5]$ and thereafter, more broadly, in the evaluation and management of trauma patients $[6,7]$.

In fact, US applications have rapidly extended from diagnosis and initial assessment in trauma to US-guided and USassisted treatment options [8-10].

Furthermore, POCUS (point of care ultrasound) is a realtime evaluation and fast decision-making tool that has proven to increase therapeutic success, decrease time for diagnosis and treatment, and reduce complications associated to invasive procedures.

Surgeon-performed US is fast, accurate, and potentiates the surgeon's diagnostic capacities broadening as well as the array of therapeutic options [11-13].

Especially in the non-operative management of posttraumatic complications, the use of US is particularly suited for follow-up owing to its portability, non-invasiveness, repeatability [14]. 
Nonetheless, many argue that US has the limit of being an operator-dependent imaging technique that requires expert users. In order to overcome such frequent objection, many scientific societies and medical schools have empowered their core curricula with US anatomy courses and FAST courses, training a growing number of future doctors to use US in the everyday clinical practice [15-17]. Consequently, surgeon trainees soon became surgeon trainers [6].

Moreover, US and its use as a trauma assessment tool are a consolidated topic in the literature, while the interventional US application in the treatment of posttraumatic complications is hardly an explored issue as shown by the limited number of articles written on the subject. It is well known how easy and safe is to puncture or drain a free demarcated collection under US guidance, even with limited experience in the in-plane or out-ofplane techniques.

Based on these premises, the purpose of this review is to assess the feasibility and usefulness of interventional US in the treatment of post-traumatic complications such as retained hemothorax, occult pneumothorax, liver trauma and bilomas, non-operative management of splenic injuries and splenic abscesses, pancreatic trauma, Morel-Lavallée lesion, and softtissue abscesses.

\section{Retained Hemothorax}

Hemothorax is a frequent post-traumatic complication occurring in around $60 \%$ of polytrauma cases [18].

US can be very useful in the initial diagnosis of this condition, offering a higher sensitivity in detecting small fluid collections $(<200 \mathrm{ml})$ compared to chest X-ray (CXR) and also showing multilocular features $[10,19]$.

According to a recent prospective observational cohort study on 112 patients, no difference was found in diagnosing hemothorax when comparing clinical examination (CE) plus CXR with ultrasound alone; conversely, US has proven a higher sensitivity in diagnosing pneumothorax (PTX) and lung contusion compared to CE plus CXR [20].

The initial treatment consists of chest tube positioning and prompt pleural cavity drainage. This procedure can benefit from US assistance. Out of emergent situations, when thoracic drainage should be placed according to the ATLS-suggested rules, US-assisted thoracostomy allows the optimal positioning of the tube and immediate follow-up [21].

Studies show that in 1 to $20 \%$ of cases, chest tube drainage can fail in draining the whole collection [22], and in some cases, a residual or retained hemothorax (RH) is formed.

Furthermore, retained hemothorax, defined as a blood collection of more than $300-500 \mathrm{ml}$ in the pleural cavity persisting for at least 3 days after trauma, is an uncommon complication of chest trauma; nonetheless, there are no conclusive statistics on its incidence [23].
According to a prospective cohort study from 2011, on 633 patients who underwent thoracostomy for traumatic hemothorax, the incidence of RH was $16.7 \%$ with $10 \%$ additional complications during a time span of 28 months.

Risk factors for RH are quantity of initial blood drainage, number of tubes placed, duration of tube thoracostomy, and need for mechanical ventilation [24].

$\mathrm{RH}$ is an independent factor for empyema which occurs in a $10 \%$ of patients who undergo post-traumatic thoracostomy and pneumonia which occurs in a $19.5 \%$ of cases as assessed in a recent prospective observational American Association for the Surgery of Trauma (AAST) study [25, 26]. For this reason, hemothorax must be quickly recognized and promptly treated [27].

Initial RH treatment is prevention, through a proper and prompt chest tube positioning for the drainage of the primary post-traumatic hemothorax. As mentioned above, US-assisted drainage could be an additional option in physiologically normal patients.

Thus, a careful monitoring of a complete drainage of the bloody collection is the second step for an optimal management of hemothorax. However, CXR is not considered the gold standard for diagnosis compared to CT scans, as the latter cannot be always and systematically performed. For these reasons, US can be very useful in assessing the daily complete evacuation of hemothorax [20].

Also, when a second thoracostomy tube placement is needed, or an initially not drained small hemothorax increases and needs drainage, the invasive procedure can strongly benefit from US assistance allowing the detection of the residual or multiloculated collections and indicating the more dependent and suitable site for drainage.

Other treatment options for RH include observation, intrapleural thrombolysis, early video-assisted thoracoscopy (VATS), and thoracotomy, although very few studies and case series have investigated the most appropriate treatment strategy [23].

Anyway, it is widely agreed, that evacuation of retained hemothorax should be done early, if possible, within 3-7 days after trauma, in order to decrease complications and allow a complete clearing of the pleural cavity $[23,26,28]$.

The Eastern Association for the Surgery of Trauma (EAST) guidelines reserve no role for a second drainage in the management of a persistent retained hemothorax, with a level I of evidence [28].

Experiences with intrapleural thrombolysis are not recent and very limited [29-34], and none of the reported ones were done with US assistance. In the prospective observational study of Kimbrell and coworkers [29], intrapleural thrombolysis achieved $92 \%$ of success in patients with RH higher than $300 \mathrm{ml}$. Other series [30, 31] achieved a similar success rate. 
Oguzkaya et al. [34] retrospectively evaluated their series comparing intrapleural thrombolysis vs. VATS, with, respectively, 70 and $88 \%$ of complete radiological improvement.

A possible role for US-assisted thrombolysis might be explored, in order to improve the right placement of the tube, the daily monitoring of effectiveness and reducing both the need for chest films and CT and the time to surgical treatment (VATS), when necessary.

Thus, US should be in the surgeon armamentarium for the detection, observational follow-up, and eventual procedural US-assisted treatment of retained hemothorax. Probably, the actual main role for US is in assisting the optimal positioning of the first drainage in non-emergent situations, whenever is possible (i.e., isolated thoracic trauma without hemodynamic abnormalities).

\section{Small Pneumothorax}

Occult PTX is currently defined as a pneumothorax that is seen on chest CT, but not on plain films [28], even if accuracy of US in the detection of PTX is well documented. Management of small and occult PTX is debated and often should be tailored to the single patient. A recent EAST guideline paper on practical management of occult pneumothorax states that occult pneumothorax may be observed in a stable patient regardless of positive pressure ventilation. Scoring systems are not considered accurate in predicting which patients will need a thoracostomy tube for occult pneumothorax (level 3 evidence) [28].

Defining the size of an incomplete PTX is easily performed by bedside US, identifying the lung point sign along the intercostal spaces (Fig. 1a). Sensitivity in the detection of small anterior PTX is very high, and US can be used in monitoring in real time, spontaneous reabsorption, or aspiration $[35,36 \bullet$, 37, 38].

Moreover, as requested by the clinical situation (for instance, the need of tracheal intubation for delivering general anesthesia for surgery), US-assisted drainage of small PTX makes this procedure safe and fast, even in very critical

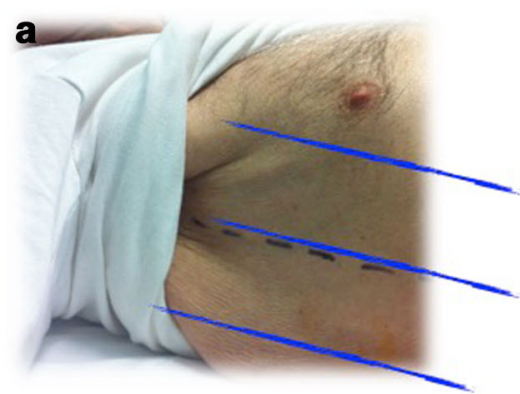

Fig. 1 a US delimitation of PTX can be performed bedside, better with the patient in the supine position. The dotted line marks the lung points detected by the US probe in every intercostal space. In this patient, PTX is at midaxillary line. b US delimitation of a small anterior PTX, extended conditions. The image of the precise circumscribed PTX site allows the placement of the needle or drain in the "free pleural air" zone, avoiding further iatrogenic lung injuries (Fig. 1b). Real-time US monitoring of the sliding lung sign with the linear probe to the sternal margin confirms the complete expansion of the lung.

\section{Liver Lesions and Bilomas}

Liver injuries are the most frequent lesions occurring after blunt abdominal trauma. In the last decades, non-operative management has been the preferred strategy even in the case of severe liver injuries. After operative treatment of liver injuries, incidence of post-traumatic biliary complications such as biloma, hemobilia, and biliary fistula, ranges from 1 to $22 \%$ [39-41]. The same injuries are reported at 2.8 to $7.4 \%$ in conservatively managed liver trauma cases [41-43].

Bilomas and extrahepatic collections due to biliary leaks could benefit from interventional maneuvers.

A biloma is currently defined as a well-demarcated bile collection located outside the biliary system or the gallbladder [44•]. Mainly, it occurs as a postoperative complication of cholecystectomy, liver resections, liver damage control surgery, or as a result of blunt liver trauma.

Bilomas are rare lesions, presenting high rates of morbidity and mortality, with a reported incidence of $4 \%(1 / 22)$ after damage control surgery for liver trauma, as shown in a Dutch series [39]. In a paper of Padalino et al., US was employed for a systematic follow-up of liver lesions after non-operative management (NOM). The incidence of biloma was $2.2 \%$ over a group of 44 patients [45].

US plays a key role in diagnosing bilomas. When in doubt, the biliary nature of the collection could be easily confirmed by a percutaneous US-guided puncture [44•]. The maneuver could be performed bedside with a 19-21 G needle. Many bilomas resolve spontaneously.

Treatment options, as for other post-traumatic biliary complications, include endoscopic retrograde cholangiopancreatography (ERCP) with sphincterotomy,

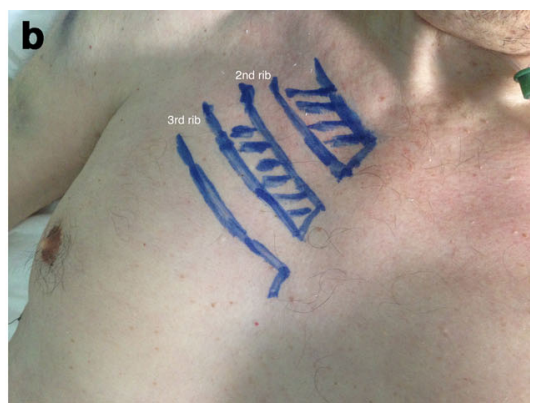

over only the first two intercostal spaces (areas with oblique lines). If clinically requested, drainage of this small PTX can be performed safely without any risk 
surgery, and percutaneous drainage. The latter could benefit from US assistance. In fact, the vast majority of intra- and extrahepatic bilomas could be drained bedside with US assistance.

US-guided percutaneous drainage or aspiration is considered the best treatment option for non-spontaneously resolving bilomas, mainly for smaller collections, which need an accurate localization by means of US [44•].

\section{NOM of the Spleen and Splenic Abscesses}

The spleen is the second most injured organ in blunt abdominal trauma [46]. Over time, spleen injury management has shifted from operative management (OM) to NOM.

Recent guidelines suggest NOM as an optimal treatment in stable patients [47], and early FAST can quickly select patients as candidates for OM, instead of NOM, allowing an adequate selection which is crucial for the successful outcome of this treatment $[48,49]$.

When surgery is needed, post-splenectomy collections could benefit from US-guided drainage, as for any other intra-abdominal collection.

Complications after splenic NOM occur in a $17.6 \%$ of adults [9].

In particular, most frequent complications in postembolization are abscesses and splenic infarction. They have reported rates ranging between 3 and $14 \%$ [50, 51]. A recent review over 1085 patients treated by NOM, 88 of whom submitted to angioembolization (AE), reports a complication rate of $14 \%$ after AE. In particular, splenic infarction accounted for $2.3 \%$ after AE, splenic abscess $6.8 \%$, contrast-induced renal insufficiency $2.3 \%$, and late development of splenic cyst $2.3 \%$ [51]. Splenic infarction requires observation or surgery. The latter is frequently required also for splenic abscesses, mainly when it relates to a bacterial infection on a splenic infarction.

US-guided percutaneous drainage or fine needle aspiration of non-traumatic splenic abscesses is considered anyway a reliable technique, with high success rates and cost-effectiveness, as compared to surgery $[52,53]$.

Therefore, this technique might be an advisable option for managing post-traumatic splenic abscesses following NOM. Theoretically, drainage of a post-AE abscess could be more difficult inasmuch as infected ischemic splenic tissue has a different density than a simple pyogenic abscess.

Notwithstanding, no specific literature was found about percutaneous drainage of splenic abscesses after NOM.

\section{Pancreatic Trauma}

The incidence of pancreatic injuries, following blunt abdominal trauma is low $(0.4 \%)$ [54]. The rarity of these lesions can lead to late diagnosis and delayed treatment. Clinical examination and laboratory tests, such as increasing amylase, are not specific [55]. Major prognostic factor for pancreas injuries is the main pancreatic duct lesion $[55,56]$. In the hemodynamically stable patient, CT scan is considered the first-line imaging modality to assess other organ injuries and lesions of the pancreatic duct. These lesions can also be investigated through ERCP or MRCP (magnetic resonance cholangiopancreatography). Conversely, US has a limited role, but could be very useful in the initial assessment and follow-up of post-traumatic complications such as pseudocysts, peripancreatic fluid collections, intra-abdominal abscesses, and pseudoaneurysms.

It is well established that, for all lesions without any main pancreatic duct injury (grade I-II AAST-OIS), simple drainage is the treatment of choice, eventually associated with pancreatic duct stenting in more advanced grades [56]. Looking at the WTA algorithm [57], US can play a monitoring role in the expectant non-operative management cases, and after surgery, the all-time simple drainage is the chosen option (grade I-II, some grade III-IV right to SMV).

In all these cases, US can monitor a successful evolution and also play a role in treatment. Indeed, most frequent complications from pancreatic injury are persistent pancreatic fistulas and pseudocysts.

Concerning pseudocyst treatment, percutaneous USguided pseudocyst drainage is considered a feasible and safe procedure [58]. Especially in recent years, this procedure has been increasingly used in clinical settings, even though few cases have been published in the literature, and no official recommendation has been established, yet [59].

In a recent systematic review by Teoh, endoscopic, percutaneous, and surgical treatments of pseudocysts are compared. There is no consensus whether surgical drainage of pancreatic pseudocysts is superior to percutaneous procedures. However, surgical drainage is preferred in some cases in order to prevent the development of external pancreatic fistulas. Endoscopic treatment, on the other hand, is feasible in selected cases depending on cyst localization and among endoscopic procedures; EUS-guided drainage could be safer than EGD for non-bulging cysts. Currently, there is a lack of consensus in the best practice for pseudocyst drainage [60 ${ }^{\bullet}$. The procedure of choice depends on different factors such as patient's global condition, cyst location, number, and size [58]. US-guided drainage is one of the available options.

\section{Diagnostic Peritoneal Aspiration in Blunt Abdominal Trauma}

Diagnostic peritoneal lavage (DPL) has played for many years a pivotal role in abdominal trauma management, while, nowadays, it is quite completely overtaken by FAST. Notwithstanding, sometimes the confirmed presence of intraperitoneal bleeding is not ruled out by 
FAST, or the nature of the free peritoneal fluid detected by US or CT remains uncertain. For example, this could be the case of suspected hollow viscus injuries, delayed diagnosis of bladder rupture, free fluid in injured cirrhotic patients, etc. In these situations, DPL or diagnostic peritoneal aspiration (DPA) could be an option.

Surprisingly, the literature about DPA in trauma patients is very poor. Heetveld et al. [61] included DPA in the algorithm for pelvic trauma management as an alternative to FAST. Kuncir and Velmahos [62], in a prospective observational study, concluded that DPA was accurate, fast, safe, and superior to FAST for the diagnosis of abdominal blood as the source of hemodynamic instability in the specific population of hypotensive blunt multitrauma patients. In both studies, DPA was performed blindly according to standard closed technique used for DPL [61, 62].

No published series were found about the use of USguided DPA in trauma patients. A preliminary communication concerning 79 patients, systematically submitted to US-guided DPA for acute non-traumatic abdominal conditions, reported a $98.7 \%$ feasibility rate of the maneuver and an overall rate of clinical decisions impacted by a USDPA of $58.9 \%$ [63]. These findings suggest that this technique might be easily applied in trauma patients, when indicated, contributing to shorten the decisionmaking process.

\section{Morel-Lavallée Lesion}

Morel-Lavallée lesion (MLL) is a rare complication of direct blunt trauma and the result of a closed degloving injury. Trauma mechanism involves tangential shear forces, and in $50 \%$ of cases, a high energy impact is the cause for this soft tissue lesion. The lower limb is the most frequent zone involved, especially the great trochanter area. Pelvic or acetabular fracture is typically associated, but contact sports are increasingly the cause [64].

MLL consists of a cystic cavity created by the detachment of the hypodermis from the underlying fascia. The cavity that is usually formed is filled with blood and lymph derived by the teared vessels and necrotic fat.

Diagnosis and treatment are frequently delayed, because the lesion usually develops several days after the trauma [65], increasing the risk of infection [66]. Incidence and the natural history of this lesion are unknown since only the case series is reported in the literature on this topic; although, patients are mainly female and with a BMI higher than $25[64,67 \cdot]$. In some patients, the lesion volume spontaneously decreases over time or remain stable, whereas in other cases, it progressively expands or assumes a recurrent pattern [64].
Since MLL is associated with blunt high energy trauma, it is fundamental to assess the presence of underlying associated injuries [68].

A history of recent trauma and clinical examination is the first aspect to consider in order to assess MLL for diagnosis. However, ultrasound and MRI can be crucial for definitive diagnosis.

MRI is the most specific diagnostic exam in order to differentiate MLL from abscesses, hematomas, lipomas and pseudo-lipomas, soft tissue tumors, fat necrosis, and bursitis $[67 \bullet]$.

Ultrasound assessment can be very useful showing an anechoic or hypoechoic cavity containing fluid with hyperechoic nodules representing fat remnants [69].

The shape of MLL varies from lobular, to fusiform and flat, located between the fascia and hypodermis [69]. Deformability under probe graduate compression is a specific US finding.

So far, there is no unanimous consensus on treatment options available which include rest, compressive bandaging, percutaneous drainage plus skin debridement, serial aspiration, open surgery and debridement, and percutaneous sclerodesis with different agents as talc, alcohol, doxycycline, and sotradechol foam $[67 \cdot, 70,71]$.

The goal of all techniques is both to obtain the collection drainage or reabsorption and prevent infection.

To our knowledge, only two studies concerning full USguided MLL treatment are reported in the literature [72, 73]. Isaacson and Stavas performed a successful US-guided drainage with alcohol injection-reaspiration of a MLL of the right lateral thigh [72]. Luria et al. treated four patients with MLL by image-guided drainage and percutaneous talc injection, with a complete resolution after 14-42 months [73].

Furthermore, US-assisted drainage of MLL was performed on eight patients by Zhong et al., for whom US was used to identify the most suitable site for a $2-\mathrm{cm}$ incision for suction, irrigation, and drain positioning [65].

Lastly, compared to open surgical treatment, US-guided or assisted MLL treatment could involve minimum invasiveness being advantageous in this type of lesions where vascularization is compromised [65].

Also, US could quickly assess undrained areas and the need for repeated follow-up [74].

\section{Soft-Tissue Abscesses}

Soft-tissue abscesses are common findings in clinical practice and consist of an inflammatory process that determines the formation of a pus-filled cavity. According to an epidemiologic study from 2009, in the time span between 1996 and 2005, the number of emergency department (ED) accesses due to abscesses, doubled [75]. 
In trauma settings, abscesses can complicate minor soft tissue blunt injuries, deep or superficial foreign body retention, degloving injuries as MLL (see above), and flap skin wounds or reconstructions.

Owing to its high sensitivity, even in comparison with CT scans, US is considered the imaging of choice for diagnosis and treatment of soft tissue conditions, as assessed in the ABSCESS (applied bedside sonography for convenient evaluation of superficial soft tissue infections) prospective clinical trial [76]. In fact, US can distinguish solid lesions from cystic ones, and among these, it contributes to differentiating abscesses from other conditions such as cellulitis, foreign bodies, or fasciitis, leading to proper treatment [76-78].

An ancient Latin aphorism suggests: "Ubi pus, ibi evacua" (where there is pus, there evacuate it), and nowadays, US-guided percutaneous drainage or aspiration of soft tissue abscesses is a feasible option thanks to its advantages such as portability, direct visualization of the abscess cavity precise drainage positioning, and immediate follow-up. This procedure reduces hospital admissions, offering shorter recovery, allowing everyday activities, and reducing complications such as injuries of adjacent structures. For these reasons, patients' satisfaction is usually high [79].

In a 24-month prospective observational study, 40 patients were assessed by bedside US performed by novices for the detection of soft tissue abscesses [80]. This study showed an increasing diagnostic accuracy in novice ultrasonographers. Also, US-guided abscess drainage proved to be an easily learned procedure.

No randomized study has been reported in the literature, neither post-traumatic abscesses have been studied as specific pathologic entities in order to assess the US-guided drainage. However, the case series reported in the literature all agree with the advantages, feasibility in clinical practice, and safety of this technique [81].

\section{Conclusions}

US is a consolidated tool for early assessment of trauma patients, and its features make this imaging technique reliable for therapeutic interventions. Adequate and early training is considered a cornerstone in allowing this technique to be mastered by non-radiology specialists, as well as residents. In particular, surgeon-performed US can really impact on daily management of critically ill patients. Studies on the use of ultrasound-guided procedures and their effectiveness in the treatment of post-traumatic complications are scarcely found in the literature; even though, these techniques are suitable for a multitude of indications and can provide safer and costeffective patient management.

\section{Compliance with Ethical Standards}

Conflict of Interest Drs. Zago, Bozzo, and Mariani declare no conflicts of interest relevant to this manuscript.

Human and Animal Rights and Informed Consent This article does not contain any studies with human or animal subjects performed by any of the authors.

\section{References}

Papers of particular interest, published recently, have been highlighted as:

- Of importance

1. Rozycki GS. Surgeon-performed ultrasound: its use in clinical practice. Ann Surg. 1998;228(1):16-28. doi:10.1097/00000658199807000-00004.

2. Dehqanzada ZA, Meisinger Q, Doucet J, Smith A, Casola G, Coimbra R. Complete ultrasonography of trauma in screening blunt abdominal trauma patients is equivalent to computed tomographic scanning while reducing radiation exposure and cost. J Trauma Acute Care Surg. 2015;79(2):199-205. doi:10.1097 /TA.0000000000000715.

3. Rozycki GS, Ochsner MG, Jaffin JH, Champion HR. Prospective evaluation of surgeons' use of ultrasound in the evaluation of trauma patients. J Trauma. 1993;34(4):516-26. discussion 526-527.

4. Scalea TM, Rodriguez A, Chiu WC, Brenneman FD, Fallon Jr WF, Kato K, et al. Focused assessment with sonography for trauma (FAST): results from an international consensus conference. J Trauma. 1999;46(3):466-72.

5. Montoya J, Stawicki SP, Evans DC, Bahner DP, Sparks S, Sharpe RP, et al. From FAST to E-FAST: an overview of the evolution of ultrasound-based traumatic injury assessment. Eur J Trauma Emerg Surg. 2016;42(2):119-26. doi:10.1007/s00068-015-0512-1.

6. Zago M, Martinez Casas I, Pereira J, Mariani D, Silva AR, Casamassima A, et al. Tailored ultrasound learning for acute care surgeons: a review of the MUSEC (Modular UltraSound ESTES Course) project. Eur J Trauma Emerg Surg. 2016;42:161-68.

7. Zago M. Time for a comprehensive ultrasound-enhanced trauma management. Eur J Trauma Emerg Surg. 2009;35:339-40.

8. Holm H, Skjoldbye B. Interventional ultrasound. Ultrasound Med Biol. 1996;22(7):773-89.

9. Goffette PP. Imaging and intervention in post-traumatic complications (delayed intervention). Emerg Radiol Imaging Interv. 2007: 61-98. doi:10.1007/978-3-540-68908-9 4.

10. Rozycki GS, Feliciano DV, Davis TP. Ultrasound as used in thoracoabdominal trauma. Surg Clin North Am. 1998;78(2):295310. doi:10.1016/S0039-6109(05)70314-5.

11. Rozycki GS, Newman PG. Surgeon-performed ultrasound for the assessment of abdominal injuries. Adv Surg. 1999;33:243-59.

12. Rozycki GS, Ballard RB, Feliciano DV, Schmidt JA, Pennington SD. Surgeon-performed ultrasound for the assessment of truncal injuries: lessons learned from 1540 patients. Ann Surg. 1998;228(4):557-67. doi:10.1097/00000658-199810000-00012.

13. Nicola R, Dogra V. Ultrasound: the triage tool in the emergency department: using ultrasound first. Br J Radiol. 2015:20150790. doi:10.1259/bjr.20150790.

14. Rozycki GS, Knudson MM, Shackford SR, Dicker R. Surgeonperformed bedside organ assessment with sonography after trauma 
(BOAST): a pilot study from the WTA Multicenter Group. J Trauma. 2005;59(6):1356-64. doi:10.1097/01.ta.0000197825.48451.74.

15. Sokpoleak S, Patel RM, Orenbaugh S. Ultrasound imaging in medical student education: impact on learning anatomy and physical diagnosis. Anat Sci Educ. 2016. doi:10.1002/ase.1630.

16. Dreher SM, Dephilip R, Bahner D. Ultrasound exposure during gross anatomy. J Emerg Med. 2014;46(2):231-40. doi:10.1016/j. jemermed.2013.08.028.

17. Moscova M, Bryce DA, Sindhusake D, Young N. Integration of medical imaging including ultrasound into a new clinical anatomy curriculum. Anat Sci Educ. 2015;8(3):205-20. doi:10.1002/ase.1481.

18. Richardson JD, Miller FB, Carrillo EH, Spain D. Complex thoracic injuries. Surg Clin North Am. 1996;76(4):725-48. doi:10.1016 /S0039-6109(05)70477-1.

19. Davis K, Rozycki GS. Acute care surgery in evolution. Crit Care Med. 2010;38(9):S405-10. doi:10.1097/CCM.0b013e3181ec55c8.

20. Hyacinthe AC, Broux C, Francony G, Genty C, Bouzat P, Jacquot $\mathrm{C}$, et al. Diagnostic accuracy of ultrasonography in the acute assessment of common thoracic lesions after trauma. Chest. 2012;141(5): 1177-83. doi:10.1378/chest.11-0208

21. Liu YH, Lin YC, Liang SJ, Tu CY, Chen CH, Chen HJ, et al. Ultrasound-guided pigtail catheters for drainage of various pleural diseases. Am J Emerg Med. 2010;28(8):915-21. doi:10.1016/j. ajem.2009.04.041.

22. Ahmad T, Ahmed SW, Soomro NH, Sheikh KA. Thoracoscopic evacuation of retained post-traumatic hemothorax. J Coll Physicians Surg Pakistan. 2013;23(3):234-6. doi:10.1016/j. athoracsur.2003.11.029.

23. DuBose J, Inaba K, Demetriades D, Scalea TM, O'Connor J, Menaker J, et al. Managment of post-traumatic retained hemothorax: a prospective, observational, multicenter AAST study. J Trauma Acute Care Surg. 2012;72(1):11-22.

24. Villegas MI, Hennessey RA, Morales CH, Londono E. Risk factors associated with the development of post traumatic retained hemothorax. Eur J Trauma Emerg Surg. 2011;37(6):583-9.

25. Stewart RM, Corneille MG. Common complications following thoracic trauma: their prevention and treatment. Semin Thorac Cardiovasc Surg. 2008;20(1):69-71. doi:10.1053/j. semtcvs.2008.01.006.

26. Bradley M, Okoye O, DuBose J, Inaba K, Demetriades D, Scalea T, et al. Risk factors for post-traumatic pneumonia in patients with retained haemothorax: results of a prospective, observational AAST study. Injury. 2013;44(9):1159-64. doi:10.1016/j.injury.2013.01.032.

27. Karmy-Jones R, Holevar M, Sullivan RJ, Fleisig A, Jurkovich GJ. Residual hemothorax after chest tube placement correlates with increased risk of empyema following traumatic injury. Can Respir J. 2008;15(5):255-8.

28. Mowery NT, Gunter OI, Collier BR, Diaz JJ, Haut E, Hildreth A, et al. Practice management guidelines for management of hemothorax and occult pneumothorax. J Trauma. 2011;70(2):510-8.

29. Kimbrell BJ, Yamzon J, Petrone P, Asensio JA, Velmahos G. Intrapleural thrombolysis for the management of undrained traumatic hemothorax: a prospective observational study. J Trauma. 2007;62:1175-8

30. Jerjes-Sánchez C, Ramirez-Rivera A, Elizalde JJ. Intrapleural fibrinolysis with streptokinase as an adjunctive treatment in hemothorax and empyema: a multicenter trial. Chest. 1996;109(6):1514-9. doi:10.1378/chest.109.6.1514.

31. Inci I, Özçelik C, Ülkü R, Tuna A, Eren N. Intrapleural fibrinolytic treatment of traumatic clotted hemothorax. Chest. 1998;114(1): 160-5. doi:10.1378/chest.114.1.160.

32. Agarwal R, Aggarwal AN, Gupta D. Intrapleural fibrinolysis in clotted haemothorax. Singapore Med J. 2006;47(11):984-6.

33. Pollack JS, Passik CS. Intrapleural urokinase in the treatment of loculated pleural effusions. Chest. 1994;105:868-73.
34. Oguzkaya F, Akcali YBM. Videothoracoscopy versus intrapleural streptokinase for management of post traumatic retained hemothorax: a retrospective study of 65 cases. Injury. 2005;36:526-9.

35. Lichtenstein D, Meziere G, Biderman P, Gepner A. The "lung point": an ultrasound sign specific to pneumothorax. Intensive Care Med. 2000;26:1434-40.

36. Soldati G, Testa A, Sher S, Pignataro G, La Sala M, Silveri NG. Occult traumatic pneumothorax: diagnostic accuracy of lung ultrasonography in the emergency department. Chest. 2008;133:204-11. Clear and documented evidence about the accuracy of US in the detection and managemtn of occult pneumothorax.

37. Blaivas M, Lyon M, Duggal S. A prospective comparison of supine chest radiography and bedside ultrasound for the diagnosis of traumatic pneumothorax. Acad Emerg Med. 2005;12:844-9.

38. Casamassima A, Zago M. Thoracic views: anatomy, techniques, scanning tips and tricks, abnormal images. Essential US for Trauma: E-FAST, Ultrasound for Acute Care Surgeons. 2014.

39. Hommes M, Kazemier G, Schep NWL, Kuipers EJ, Schipper IB. Management of biliary complications following damage control surgery for liver trauma. Eur J Trauma Emerg Surg. 2013;39:511-6.

40. Moore EE, Shackford SR, Pachter HL, et al. Organ injury scaling: spleen, liver, and kidney. J Trauma. 1989;29(12):1664-6.

41. Bala M, Gazalla SA, Faroja M, Bloom AI, Zamir G, Rivkind AI, et al. Complications of high grade liver injuries: management and outcomewith focus on bile leaks. Scand J Trauma Resusc Emerg Med. 2012;20:20. doi:10.1186/1757-7241-20-20.

42. Kozar RA, Moore JB, Niles SE, Holcomb JB, Moore EE, Cothren $\mathrm{CC}$, et al. Complications of nonoperative management of highgrade blunt hepatic injuries. J Trauma. 2005;59(5):1066-71. doi:10.1097/01.ta.0000188937.75879.ab.

43. Carrillo EH, Spain DA, Wohltmann CD, Schmieg RE, Boaz PW, Miller FB, et al. Interventional techniques are useful adjuncts in nonoperative management of hepatic injuries. J Trauma. 1999;46(4):614-9.

44. Copelan A, Bahoura L, Tardy F, Kirsch M, Sokhandon F, Kapoor B. Etiology, diagnosis, and management of bilomas: a current update. Tech Vasc Interv Radiol. 2015;18(4):236-43. doi:10.1053/j. tvir.2015.07.007. This paper exaustively summarizes the diagnostical and therapeutical problems issued by bilomas. It represents a referenced and practical update on this topic.

45. Padalino P, Bomben F, Chiara O, Montagnolo G, Marini A, Zago $\mathrm{M}$, et al. Healing of blunt liver injury after non-operative management: role of ultrasonography follow-up. Eur J Trauma Emerg Surg. 2009;35:364-70.

46. Smith J, Caldwell E, D'Amours S, Jalaludin B, Sugrue M. Abdominal trauma: a disease in evolution. ANZ J Surg. 2005;75(9):790-4. doi:10.1111/j.1445-2197.2005.03524.x.

47. Stassen NA, Bhullar I, Cheng JD, Crandall ML, Friese RS, Guillamondegui OD, et al. Selective nonoperative management of blunt splenic injury: an Eastern Association for the Surgery of Trauma practice management guideline. J Trauma Acute Care Surg. 2012;73(5 Suppl 4):S294-300. doi:10.1097/TA.0b013e3182702afc.

48. Van Der Vlies CH, Van Delden OM, Punt BJ, Ponsen KJ, Reekers JA, Goslings JC. Literature review of the role of ultrasound, computed tomography, and transcatheter arterial embolization for the treatment of traumatic splenic injuries. Cardiovasc Intervent Radiol. 2010;33(6):1079-87. doi:10.1007/s00270-010-9943-6.

49. El-Matbouly M, Jabbour G, El-Menyar A, Peralta R, Abdelrahman $\mathrm{H}$, Zarour A, et al. Blunt splenic trauma: assessment, management and outcomes. Surgeon. 2016;14(1):52-8. doi:10.1016/j. surge.2015.08.001.

50. Haan JM, Biffl W, Knudson MM, Davis KA, Oka T, Majercick S, et al. Splenic embolization revisited: a multicenter review. J Trauma. 2004;56(3):542-7. doi:10.1097/01.TA.0000114069.73054.45.

51. Ekeh AP, Khalaf S, Ilyas S, Kauffman S, Walusimbi M, McCarthy MC. Complications arising from splenic artery embolization: a 
review of an 11-year experience. Am J Surg. 2013;205(3):250-4. doi:10.1016/j.amjsurg.2013.01.003.

52. Conzo G, Docimo G, Palazzo A, Della Pietra C, Stanzione F, Sciascia V, et al. The role of percutaneous US-guided drainage in the treatment of splenic abscess. Case report and review of the literature. Ann Ital Chir. 2012;83:433-6.

53. Ferraioli G, Brunetti E, Gulizia R, Mariani G, Marone P, Filice C. Management of splenic abscess: report on 16 cases from a single center. Int J Infect Dis. 2009;13(4):524-30. doi:10.1016/j. ijid.2008.08.024.

54. Akhrass R, Yaffe MB, Brandt CP, Reigle M, Fallon WF, Malangoni MA. Pancreatic trauma: a ten-year multi-institutional experience. Am Surg. 1997;63(7):598-604

55. Debi U, Kaur R, Prasad KK, Sinha SK, Sinha A, Singh K. Pancreatic trauma: a concise review. World J Gastroenterol. 2013;19(47):9003-11. doi:10.3748/wjg.v19.i47.9003.

56. Kumar A, Panda A, Gamanagatti S. Blunt pancreatic trauma: a persistent diagnostic conundrum? World J Radiol. 2016;8(2):159 73. doi:10.4329/wjr.v8.i2.159.

57. Biffl WL, Moore EE, Croce M, Davis JW, Coimbra R, KarmyJones R, et al. Western Trauma Association Critical decisions in Trauma: management of pancreatic injuries. J Trauma Acute Care Surg. 2013;75:941-6.

58. Pitchumoni CS, Agarwal N. Pancreatic pseudocysts: when and how should drainage be performed? Gastroenterol Clin North Am. 1999;28(3):615-39. doi:10.1016/S0889-8553(05)70077-7.

59. Martinez-Ramos D, Cifrian-Pérez M, Garcia-Vila JH, SalvadorSanchìs JL, Hoashi JS. Percutaneous drainage treatment of traumatic pancreatic rupture with pancreatic transection. Gastroenterol Hepatol. 2010;33(2):102-5. doi:10.1016/j.gastrohep.2009.09.004.

60. Teoh AYB, Vinay D, Jin Z-D, Kida M, Seo DW, Khek YH. Systematic review comparing endoscopic, percutaneous and surgical pancreatic pseudocyst drainage. World J Gastrointest Endosc. 2016;8(6):310-8. Even if not specifically devoted to trauma setting, this paper is an updated and rationalized review on available options for the management of pancreatic pseudocysts.

61. Heetveld MJ, Harris I, Schlaphoff G, Balogh Z, D'Amours SK, Sugrue M. Hemodynamically unstable pelvic fractures: recent care and new guidelines. World J Surg. 2004;28(9):904-9. doi:10.1007 /s00268-004-7357-9.

62. Kuncir EJ, Velmahos GC. Diagnostic peritoneal aspiration - the foster child of DPL: a prospective observational study. Int J Surg. 2007;5(3):167-71. doi:10.1016/j.ijsu.2006.06.013.

63. Zago M, Mariani D, Casamassima A, Marconi M. Impact of systematic use of US-guided DPA in the management of abdominal emergencies. Eur J Trauma Emerg Surg. 2016;42 Suppl 2:S51. doi:10.1007/s00068-016-0658-5.

64. Li H, Zhang FJ, Lei GH. Morel-Lavallée lesion. Chin Med J (Engl). 2014;127(7):1351-6. doi:10.3760/cma.j.issn.0366-6999.20131943.

65. Zhong B, Zhang C, Luo C. Percutaneous drainage of MorelLavallée lesions when the diagnosis is delayed. J Can Chiropr. 2014;57(5):356-57. doi:10.1503/cjs.034413.
66. Weiss NA, Johnson JJ, Anderson SB. Morel-Lavallée lesion initially diagnosed as quadriceps contusion: ultrasound, MRI, and importance of early intervention. West J Emerg Med. 2015;16(3):438-41. doi:10.5811/westjem.2011.5.6700.

67. Greenhill D, Haydel C, Rehman S. Management of the MorelLavallée lesion. Orthop Clin North Am. 2016;47(1):115-25. doi:10.1016/j.ocl.2015.08.012. Updated and stimulating review on this rare but sometimes challenging injury.

68. Tseng S, Tornetta P. Percutaneous management of Morel-Lavallee lesions. J Bone Joint Surg Am. 2006;88(1):92-6. doi:10.2106 /JBJS.E.00021.

69. Neal C, Jacobson JA, Brandon C, Kalume-Brigido M, Morag Y, Girish G. Sonography of Morel-Lavallée lesions. J Ultrasound Med. 2008;27(7):1077-81.

70. Bansal A, Bhatia N, Singh A, Singh AK. Doxycycline sclerodesis as a treatment option for persistent Morel-Lavallée lesions. Injury. 2013;44(1):66-9. doi:10.1016/j.injury.2011.11.024.

71. Penaud A, Quignon R, Danin A, Zakine G. Alcohol sclerodhesis: an innovative treatment for chronic Morel-Lavallée lesions. J Plast Reconstr Aesthet Surg. 2011;64(10):262-4.

72. Isaacson AJ, Stavas J. Image-guided drainage and sclerodesis of a Morel-Lavallée lesion. JVIR. 2012;10:605-6.

73. Luria S, Applbaum Y, Weil Y, Liebergall M, Peyser A. Talc sclerodhesis of persistent Morel-Lavallée lesions (posttraumatic pseudocysts): case report of 4 patients. J Orthop Trauma. 2006;20(6):435-8. doi:10.1097/00005131-200607000-00013.

74. Goodman BS, Smith MT, Mallempati S, Nuthakki P. A comparison of ultrasound and magnetic resonance imaging findings of a MorelLavallée lesion of the knee. PM R. 2013;5(1):70-3. doi:10.1016/j. pmrj.2012.08.001.

75. Taira BR, Singer AJ, Thode HC, Lee CC. National epidemiology of cutaneous abscesses: 1996 to 2005. Am J Emerg Med. 2009;27(3): 289-92. doi:10.1016/j.ajem.2008.02.027.

76. Squire BT, Fox JC, Anderson C. Abscess: applied bedside sonography for convenient evaluation of superficial soft tissue infections. Acad Emerg Med. 2005;12(7):601-6. doi:10.1197/j. aem.2005.01.016.

77. Gaspari R, Dayno M, Briones J, Blehar D. Comparison of computerized tomography and ultrasound for diagnosing soft tissue abscesses. Crit Ultrasound J. 2012;4(1):5. doi:10.1186/2036-7902-4-5.

78. Adhikari S, Blaivas M. Sonography first for subcutaneous abscess and cellulitis evaluation. J Ultrasound Med. 2012;31(10):1509-12.

79. Kjaer S, Rud B, Bay-Nielsen M. Ultrasound-guided drainage of subcutaneous abscesses on the trunk is feasible. Dan Med J. 2013;60(4):A4601.

80. Berger T, Garrido F, Green J, Lema PC, Gupta J. Bedside ultrasound performed by novices for the detection of abscess in ED patients with soft tissue infections. Am J Emerg Med. 2012;30(8): 1569-73. doi:10.1016/j.ajem.2011.08.002.

81. Sahlani L, Thompson L, Vira A, Panchal AR. Bedside ultrasound procedures: musculoskeletal and non-musculoskeletal. Eur J Trauma Emerg Surg. 2016;42(2):127-38. doi:10.1007/s00068015-0539-3. 